\title{
The evolutionary history of Drosophila buzzatii. XXI. Cumulative action of multiple sterility factors on spermatogenesis in hybrids of $D$. buzzatii and $D$. koepferae
}

\author{
H. NAVEIRA \& A. FONTDEVILA* \\ Departamento de Fundamental, Facultad de Biuologia, Universidad de Santiago de Compostela, Spain \\ * Departamento de Genética y Microbiología, Universidad Autónoma de Barcelona, Bellaterra (Barcelona), Spain
}

\begin{abstract}
The genetic basis of sterility in male hybrids of Drosophila buzzatii and D. koepferae has been investigated by assessment of the effects on spermatogenesis of substituting separate chromosome segments of the recipient species with the homologous material from the donor species, either in heterozygous (autosomes) or hemizygous (X chromosome) condition, after successive backcrossing of hybrid females to either parental species. Introgressed segments were identified by the characteristic asynapsis of the polytene chromosomes in their heterospecific regions. Except for one case, the introgression of chromosome segments either from autosome 3, 4, or 5 brings about sterility only when the introgressed segment exceeds a minimum size (threshold size). Segments of equal size frequently produce similar abnormalities, whose severity increases with the size of the introgressed segment. Apparently, throughout these autosomes of $D$. buzzatii and $D$. koepferae there are many non-allelic, minor sterility genes, whose individual segregation cannot be recognized phenotypically, and which act cumulatively on the same characteristics of spermatogenesis, each contributing a small effect to the phenotype. Accordingly, these genes should be considered as polygenes, and the type of sterility they bring about should be properly designated polygenic sterility.
\end{abstract}

Keywords: Drosophila, male hybrids, polygenes, spermatogenesis, sterility.

\section{Introduction}

Over 61 per cent of all interspecific hybridizations in the genus Drosophila which yield adult offspring give rise to sterile males but fertile females (Bock, 1984). These constitute good examples of the well-known Haldane's rule (Haldane, 1922), the genetic basis of which is still a matter for active research. It is generally agreed that many factors distributed among all the major chromosomes may cause the sterility of hybrid males [Dobzhansky, 1936; Pontecorvo, 1943; Coyne, \& Kreitman, 1986; Vigneault \& Zouros, 1986 (experiment III); Naveira \& Fontdevila, 1986; Orr, 1987, 1989a, 1989b; Zouros et al., 1988 (experiments II and III); Coyne \& Charlesworth, 1989; Orr \& Coyne, 1989]. Most contemporary authors consider that these sterility factors correspond to major genes, easily mappable by the conventional method of recombination with chromosome markers (Charlesworth et al.,
1987; Zourous et al., 1988; Coyne \& Charlesworth, 1989; Orr, 1989a, 1989b). In the hybrids of D. buzzatii and D. koepferae, however, we have found that sterility can be brought about by many factors whose individual effect cannot be recognized, and therefore cannot be mapped by the conventional methods (Naveira \& Fontdevila, 1986, 1991).

In all the above mentioned studies hybrid sterility was assessed by measuring the length of the testis, the motility of the sperm, or the ability to yield offspring, but not one of them examined the details of spermatogenesis in the hybrid males. Sterility, however, is only the final result of an abnormal spermatogenesis, whose precise departure from normality may vary according to the fertility loci affected. Many different mutations in $D$. melanogaster are known to affect spermatogenesis in a specific, clearly recognizable way (Lifschytz \& Meyer, 1977; Lindsley \& Tokuyasu, 1980). Therefore, it might be possible that the factors that bring about 
hybrid sterility could also be differentiated by their peculiar effects on spermatogenesis. In the hybrids of $D$. buzzatii and $D$. koepferae male sterility was investigated by means of the introgression in heterozygosis of different chromosome segments from one species into the other (Naveira \& Fontdevila, 1986, 1990). Our results were given therefore in terms of chromosome segments, not of genes. We found that the effect of autosomes 3 and 4 on hybrid male fertility (determined by the ability to yield offspring) most frequently depended on the size of the introgressed chromosome segment. There was generally a size-dependent threshold effect, which brought about sterility only when the threshold was exceeded. Only a single major sterility gene, able to produce sterility by itself, was found. In addition, it was determined that different segments that separately allowed fertility could co-operate to cause sterility if simultaneously introgressed in the same male, provided that their added sizes exceeded the threshold. Our conclusion was that many different minor, and apparently equivalent factors of sterility were dispersed throughout chromosomes 3 and 4, and probably also over the other autosomes. In an effort to understand the effects of these factors we have studied the spermatogenesis of introgressive hybrid males of $D$. buzzatii and $D$. koepferae. It might be that the sterility produced by different chromosome segments of similar size could be caused by entirely different defects in spermatogensis. Thus, the sterility factors of those segments should no longer be regarded as equivalent. In this paper we show that they are indeed equivalent, and that they constitute a group of non-allelic genes which affect the same characteristics of spermatogenesis, each contributing a relatively small effect to the phenotype. According to these properties, these sterility factors should be called polygenes. We have already presented some preliminary evidence (Naveira et al., 1984, 1989), showing that very similar abnormalities in spermatogenesis were produced by the separate introgression of two different chromosome inversions of similar size from $D$. koepferae into $D$. buzzatii, one in chromosome 3 and another in chromosome 5. In addition, analysis of the effects of two other inversions from $D$. koepferae showed that the larger the inversion introgressed in $D$. buzzatii, the more severe were the abnormalities it produced. Now we present the results of a much more extensive study involving mainly homosequential chromosomes.

\section{Materials and methods}

Drosophila buzzatii and D. koepferae (formerly $D$. serido from Argentina) are two sibling species which coexist in many of the arid and semiarid zones of Andean Bolivia and Northwest Argentina (Fontdevila et al., 1988). They have the standard $D$. repleta group polytene karyotype, consisting of five rod-like chromosomes and a tiny dot-like chromosome. Number 1 corresponds to the $\mathrm{X}$, numbers $2-5$ to the long acrocentric autosomes, and number 6 to the dot. Each chromosome is subdivided into cytological intervals, identified by capital letters and numbers (Fig. 1a). Each interval contains a series of bands, which are identified by lower-case letters, in alphabetical order from telomere to centromere. Polytene chromosome maps for each species were constructed using the established descriptions (Wharton, 1942; Ruiz et al., 1982) for reference.

\section{Origin of the strains.}

Only one strain of D. koeferae $(\mathrm{k} 0)$ and two strains of D. buzzatii (b0 and bIII) were used for the experiments described in this paper. Strains k0 and bIII were derived in a similar way from two flies (male and virgin female) taken from a population cage founded by a large sample of either D. koepferae or D. buzzatii collected in December 1979 by A. Fontdevila and A. Ruiz in the locality of San Luis (Argentina), and kept by mass-matings thereafter. Strain b0 was also derived from two flies taken from the population cage of San Luis but it was maintained by brother-sister matings during several generations prior to mass-matings.

\section{Genetics analysis}

Hybrids are not found in nature, but laboratory crosses between $D$. koepferae females and $D$. buzzatii males yield an $F_{1}$ of sterile hybrid males and fertile hybrid females. Reciprocal crosses never produced offspring. $F_{1}$ hybrid females were backcrossed with either parental species, and this backcrossing was continued for several generations, giving rise to different introgression lines where the effect of different chromosome segments on spermatogenesis of the hybrid male could be separately analysed (Fig. 1b). The rationale of the method is to reduce progressively, through repeated backcrosses and the accompanying recombination, the length of the introgressed segments, and to observe the consequences of this reduction on the spermatogenesis of the hybrid males. Asynapsis of homologous polytene chromosomes of D.buzzatii and D. koepferae (Fig. 1c and 1d) was used to identify the segments introgressed in each line, as described in Naveira \& Fontdevila (1986). The validity of this method for mapping gene differences between species has been demonstrated already (Naveira et al., 1986) 
(a)
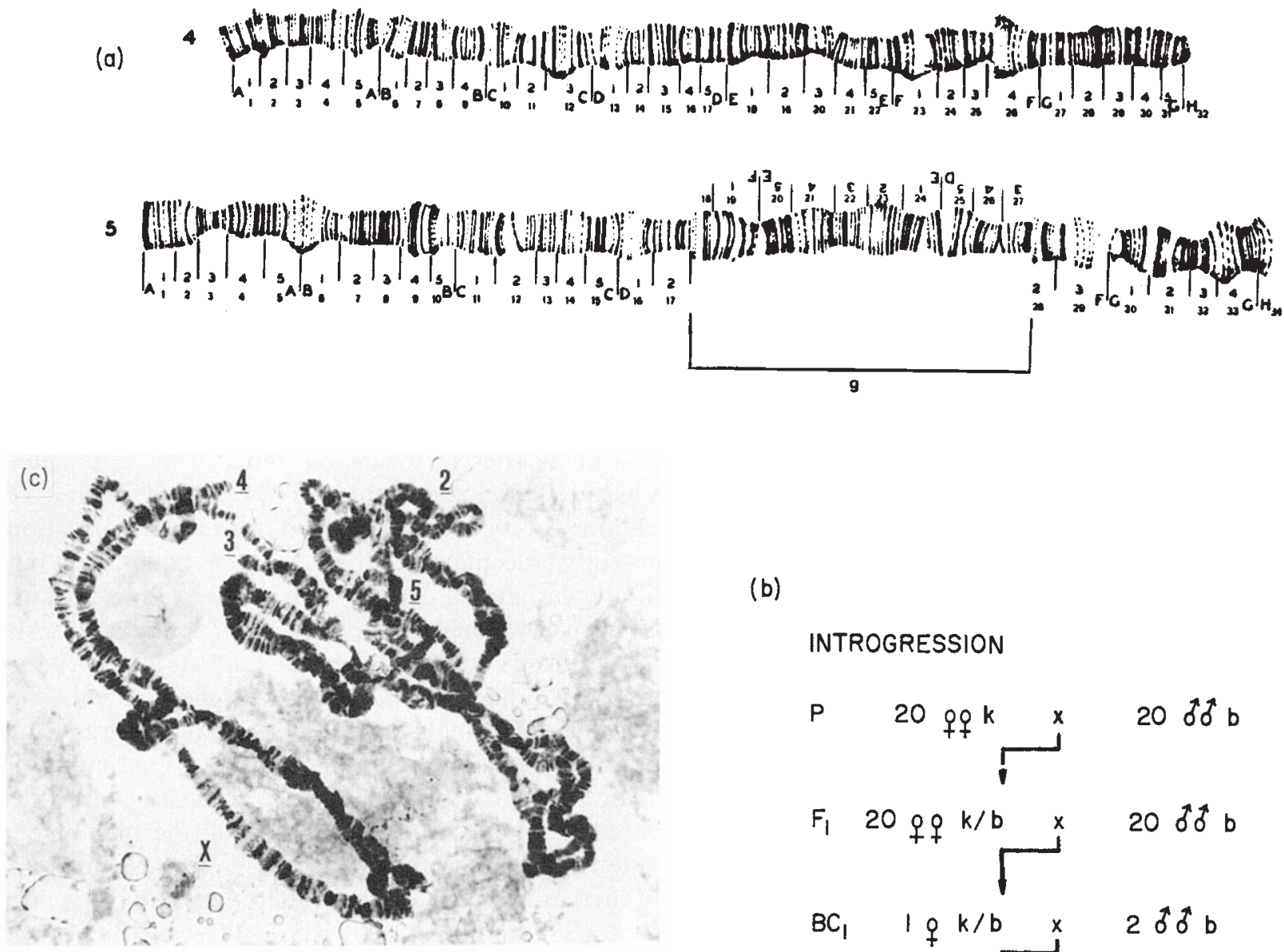

(b)

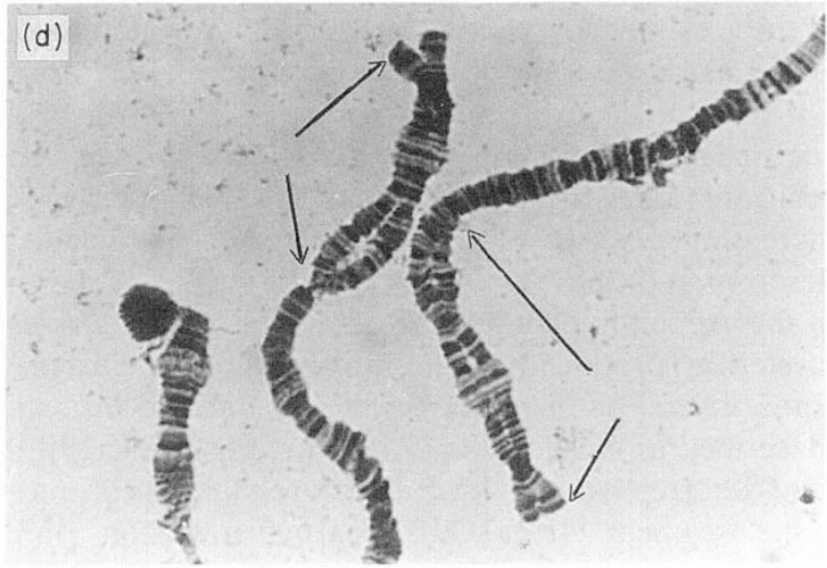

INTROGRESSION

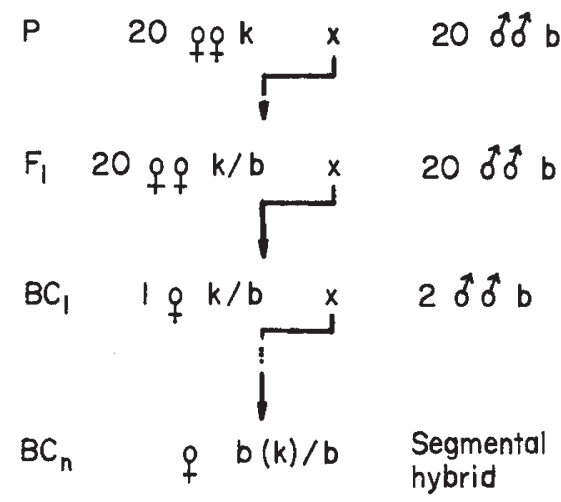

ASSESSMENT OF THE EFFECT ON SPERMATOGENESIS

Fig. 1. Method of diagnosis of the genotype and mating protocol for introgression and assessment of the effect on spermatogenesis of selected chromosome segments. (a) Maps of polytene chromosomes 3, 4, and 5 of D. buzzatii, showing their characteristic sequence of bands and interbands, where any chromosome segment may be referred to. (b) Mating protocol for the production of hybrids with selected chromosome segments from $D$. koepferae introgressed in heterozygosis into $D$. buzzatii (segmental hybrids); only one autosome pair is represented; $\mathrm{b}=D$. buzzatii; $\mathrm{k}=D$. koepferae; $\mathrm{b}(\mathrm{k})=D$. buzzatii chromosome with a segment from $D$. koepferae; $\mathrm{P}=$ parental generation; $\mathrm{F}_{1}=$ first generation; $\mathrm{BC}=$ backcross. (c) Polytene chromosomes of an $\mathrm{F}_{1}$ hybrid male, showing the asynapsis of all the homologous chromosome of the two species. (d) Polytene chromosome 5 of two different nuclei in a hybrid male of $D$. buzzatii introgressed with the segment $5 \mathrm{~A}-\mathrm{C} 2 \mathrm{~b}$ from $D$. koepferae, showing the diagnostic asynapsis only in the heterospecific region of the homologues (arrows). 
and recently ratified by in situ hybridizations (Labrador et al., 1990). Technical details concerning the experimental cultures of Drosophila, the crossing design for the introgressive hybridization, and the preparation of polytene chromosomes from salivary glands and Malpighian tubes are given elsewhere (Naveira \& Fontdevila, 1986; Naveira et al., 1986). Three introgressive hybridizations were performed: $\mathrm{k} 0$ (donor species) into either b0 or bIII (recipient species), and b0 (donor species) into k0 (recipient species). Introgression of bIII into $\mathrm{k} 0$ was not successful. After repeated backcrosses only separate segments of either chromosome 3,4 , or 5 of the donor species were left, in heterozygous condition, in the genetic background of the recipient species (segmental hybrids). Chromosomes 3 and 4 of $D$. koepferae and $D$. buzzatii are homosequential in the populations of San Luis, whereas chromosome 5 of $D$. buzzatii is fixed for inversion 5g (Ruiz et al., 1982). Thus the standard arrangement of chromosome 5 in $D$. koepferae is designated $5 \bar{g}$, to indicate the lack of inversion g. No evidence of selective elimination of incompatible elements of the genome in the backcrossing procedure has been found. Chromosome Y could not be investigated $\left(F_{1}\right.$ hybrid males are always sterile). Chromosome 2 is fixed for a series of species-specific inversions which make its genetic dissection impossible, and lead, when introgressed as a block, to the most extreme type of hybrid male sterility (Naveira et al., 1984, 1989). Introgression of chromosome 6 always allowed hybrid male fertility, with no apparent changes in spermatogenesis. In all the results that follow, chromosomes Y, 2, and 6 were always homozygous $D$. buzzatii.

\section{Analysis of spermatogenesis.}

Thirty offspring males, 8-10 days old (kept in vials without females from the time of their emergence), from each selected backcrossed hybrid female were dissected in Ringer solution, their testes extracted and placed on a slide in acetic-acid 50 per cent for $1 \mathrm{~min}$, followed by acetic-orcein 50 per cent for $4 \mathrm{~min}$, and finally in lactic-acetic-orcein for $1 \mathrm{~min}$. Later, a coverslip was placed on the preparation and it was pressed gently in order to make the material spread a little. The results of this simple procedure are comparable in many respects to those obtained by the more elaborate technique of BAO staining (Naveira et al., 1984), although it does not allow the precise quantification of the number of nuclei per cyst in early spermatids that was possible with BAO. Controls of these experiments were performed by analysing 30 offspring males of non-hybrid sisters of the selected hybrid females. At least two replicates were run of each introgressed segment, thus a total of 60 males were examined.

\section{Results}

Previous investigations have shown the features of the spermatogenesis of sterile hybrids produced by the introgression of species-specific inversions from $D$. koepferae into D. buzzatii (Naveira et al., 1984, 1989). Three basic classes of hybrid male sterility were found: $2 \mathrm{~b} / \mathrm{k}, 3 \mathrm{k}^{2}-5 \mathrm{~g} w$, and $4 \mathrm{~m}$, corresponding to the introgression of inversions either $2 j^{9} m^{9} n^{9}$ or $2 j^{9} k^{9}$, either $3 \mathrm{k}^{2}$ or $5 \overline{\mathrm{gw}}$, and $4 \mathrm{~m}$, respectively (inversions described in Ruiz et al., 1982). Each class of hybrid male sterility corresponded to a more or less normal multivariate distribution, defined by an average and a variance for each of a series of diagnostic traits in the spermatogenesis. Therefore, there were a certain degree of random, non-genetically based phenotypic variation among sterile males of the same genotypic class, but differences among classes were still very conspicuous. We have now analysed the patterns of spermatogenesis of hybrids produced by the independent introgression of several homosequential chromosome segments. We find that following the introgression of progressively larger chromosome segments there is a continuum of changes from virtually normal spermatogenesis to extremely abnormal. Nevertheless, all the phenotypic patterns can be grouped into five basic class-intervals (in increasing order of abnormality): Fertile (F), semisterile (SS), sterile $4 \mathrm{~m}(4 \mathrm{~m})$, sterile $3 \mathrm{k}^{2}-5 \mathrm{gw}\left(3 \mathrm{k}^{2}-5 \mathrm{~g} w\right)$, and sterile $2 b / k(2 b / k)$. At the same time, within some of these classes several subclasses could be indentified, which mark the transition to more abnormal patterns. On the whole, up to nine different classes of hybrid spermatogenesis could be defined, which received arbitrary values from 1 to 9 for statistical analyses, with increasing severity of the abnormalities. A detailed description of these classes of spermatogenesis is given in the Appendix. Under this classification, the classes of sterility produced by the introgression of chromosome inversions from $D$. koepferae into $D$. buzzatii (described in full detail in Naveira et al., 1984, 1989) would correspond to $4 \mathrm{~m} / 2$ (introgression of chromosome segment $4 \mathrm{E} 2 \mathrm{a}-\mathrm{G} 2 \mathrm{f}$, bearing inversion $4 \mathrm{~m}$ ), $3 \mathrm{k}^{2}-5 \mathrm{gw} / 1$ (introgression of either segment $3 \mathrm{C} 5 \mathrm{a}-\mathrm{Glb}$, with inversion $3 \mathrm{k}^{2}$, or segment $5 \mathrm{C} 5 \mathrm{~d}-\mathrm{F} 2 \mathrm{~h}$, with inversion $5 \overline{\mathrm{gw}}$ ), and $2 \mathrm{~b} / \mathrm{k}$ (introgression of segment $2 \mathrm{C} 2 \mathrm{~b}-\mathrm{F} 4 \mathrm{a}$, with inversions $2 \mathrm{j}^{9} \mathrm{~m}^{9} \mathrm{n}^{9}$, or $2 \mathrm{~B} 2 \mathrm{c}-\mathrm{F} 4 \mathrm{a}$, with inversions $\left.2 j^{9} k^{9}\right)$. All these patterns of spermatogenesis, together with any of the others included in our classification, can be reproduced by the introgression of homosequential chromosome segments of 
appropriate size. None of these patterns was ever observed in the controls (pure D. buzzatii males), whose sterility, when found, was of an entirely different kind (Naveira et al., 1984).

Table 1 shows the frequencies of the basic classes of anomalous spermatogenesis observed in the male offspring of hybrid mothers of $D$. buzzatii (strain bIII) introgressed with several separate homosequential segments of chromosomes 3 and 4 from D. koepferae. For each offspring the fraction of males with anomalous spermatogenesis is indicated (estimated from a sample of 30 dissected males), considering as abnormal any male whose seminal vesicles were not full of huge bundles of motile sperm (fertile type of spermatogenesis). This fraction should reflect the segregation in the offspring of each hybrid mother of the pure $D$. buzzatii chromosome and its hybrid homologue. A maximum of 12 males with anomalous spermatogenesis were analysed in detail, from each male offspring sample, and each assigned to one of the basic classes of abnormal spermatogenesis. As shown in Table 1, of the four basic classes of abnormal spermatogenesis only the most aberrant one, $2 b / k$, was never observed in our samples. In some of these samples, namely those corresponding to the largest introgressed segments, several classes of spermatogenesis were observed. This heterogeneity might be due either to variable expression associated with the same karyotype or to genetic recombination of the $D$. koepferae and $D$. buzzatii genomes in the offspring of the hybrid mother. Table 2 shows that the second explanation is correct. We determined the karyotypes of the males in the different samples by analysis of the polytene chromosomes of their Malpighian tubules, and although the determination of the extent of the introgressed chromosome segments cannot be as precise as in polytene chromosomes of third instar larvae, it is clearly demonstrated that many of them are indeed recombinants, and that there is a strong association between the severity of the abnormalities in spermatogenesis (expressed as arbitrary units from 1 to 9) and the size of the introgressed segment (Spearman's rank correlation coefficient: $r_{\mathrm{s}}=0.80$, and $r_{\mathrm{s}}=0.97$, for chromosomes 3 and 4, respectively; both of them significant at the 0.1 per cent level), which points to a cumulative effect of the underlying genetics factors.

Table 1 Relative frequency of the basic types of anomalous spermatogenesis observed in the male offspring of hybrids mothers of D. buzzatii (strain bIII) introgressed with several separate homosequential segments of chromosome 3 and 4 from $D$. koepferae (strain $\mathrm{k} 0$ ). The size of the chromosome segments is given as a percentage of the total length of the haploid polytene karyotype

\begin{tabular}{|c|c|c|c|c|c|c|c|}
\hline \multirow{2}{*}{$\begin{array}{l}\text { Introgressed } \\
\text { segment in the } \\
\text { hybrid mother }\end{array}$} & \multirow{2}{*}{$\begin{array}{l}\text { Size of the } \\
\text { segment }\end{array}$} & \multirow{2}{*}{$\begin{array}{l}\text { Fraction of } \\
\text { male offspring } \\
\text { with anomalous } \\
\text { spermatogenesis }\end{array}$} & \multicolumn{5}{|c|}{$\begin{array}{l}\text { Number of males with the } \\
\text { indicated type of abnormal } \\
\text { spermatogenesis }\end{array}$} \\
\hline & & & $2 b / k$ & $3 \mathrm{k}^{2}-5 \bar{g} \mathrm{w}$ & $4 \mathrm{~m}$ & SS & Total \\
\hline $3 \mathrm{Ala}-\mathrm{H}\left({ }^{*}\right)$ & 21.0 & 0.73 & 0 & 4 & 7 & 1 & 12 \\
\hline $3 \mathrm{C} 3 \mathrm{~b}-\mathrm{H}$ & 13.4 & 0.52 & 0 & 9 & 3 & 0 & 12 \\
\hline $3 \mathrm{Ala}-\mathrm{E} 2 \mathrm{f}$ & 12.4 & 0.47 & 0 & 8 & 4 & 0 & 12 \\
\hline 3Ala-D1b & 9.1 & 0.50 & 0 & 0 & 10 & 2 & 12 \\
\hline $3 \mathrm{E} 1 \mathrm{e}-\mathrm{G} 3 \mathrm{c}$ & 7.2 & 0.50 & 0 & 0 & 0 & 12 & 12 \\
\hline $3 \mathrm{C} 5 \mathrm{~d}-\mathrm{F} 2 \mathrm{a}$ & 6.6 & 0.37 & 0 & 0 & 11 & 0 & 11 \\
\hline $3 \mathrm{Ala}-\mathrm{C} 1 \mathrm{c}$ & 6.6 & 0.10 & 0 & 0 & 0 & 3 & 3 \\
\hline $3 F 1 c-H$ & 6.5 & 0.00 & - & - & - & - & - \\
\hline $3 \mathrm{Cle}-\mathrm{E} 2 \mathrm{f}$ & 5.7 & 0.47 & 0 & 0 & 11 & 1 & 12 \\
\hline $3 \mathrm{D} 1 \mathrm{~b}-\mathrm{E} 4 \mathrm{~d}$ & $4 \cdot 4$ & 0.57 & 0 & 0 & 0 & 12 & 12 \\
\hline $3 C 1 c-C 4 b$ & 1.9 & 0.00 & - & - & - & - & - \\
\hline $4 \mathrm{Ala}-\mathrm{H}\left(^{*}\right)$ & $16 \cdot 8$ & 0.53 & 0 & 5 & 5 & 2 & 12 \\
\hline $4 B 2 c-F 4 f$ & 10.7 & 0.40 & 0 & 9 & 2 & 1 & 12 \\
\hline $4 \mathrm{D} 3 \mathrm{~b}-\mathrm{H}$ & 9.4 & 0.47 & 0 & 0 & 12 & 0 & 12 \\
\hline $4 \mathrm{~F} 1 \mathrm{c}-\mathrm{H}$ & 5.0 & 0.40 & 0 & 0 & 0 & 12 & 12 \\
\hline $4 E 3 f-G 2 a$ & 4.3 & 0.50 & 0 & 0 & 0 & 12 & 12 \\
\hline $4 \mathrm{~F} 4 \mathrm{a}-\mathrm{H}$ & 3.6 & 0.03 & 0 & 0 & 0 & 1 & 1 \\
\hline $4 F 4 d-H$ & 3.1 & 0.00 & - & - & - & - & - \\
\hline
\end{tabular}

*Whole chromosome. 
However, this association is not absolute. For example (Table 2), segment 3E4-H, which includes the centromere of chromosome 3 and represents 7.8 per cent of the haploid karyotype, gives rise to phenotype SS/1 (semisterile), but segment 3C5-F2, which amounts only to 6.6 per cent and occupies an intermediate position on the chromosome, gives rise to $4 \mathrm{~m} / 2$ (complete sterility). Similarly, 3A-C3, which includes the telomere of chromosome 3 and represents 8.2 per cent of the haploid karyotype, gives rise to the phenotype SS/1, whereas $4 \mathrm{~A}-\mathrm{D} 3$, which amounts to 7.8 per cent and includes the telomere of chromosome 4 , gives rise to $4 \mathrm{~m} / 2$. Other similar examples can be found in Table 2. Apparently, the effect of an introgressed chromosome segment on spermatogenesis depends not only on its size, but also on its position on the chromosome, and on whether it is a chromosome 3 or 4 segment, which most probably reflects the heterogeneity in the distribution of the underlying genetic factors. Despite this, it can be observed that when the segment introgressed in the hybrid mother is partitioned by crossing over, the spermatogenesis phenotypes associated with the recombinant products are never more abnormal than the phenotype associated with the intact segment (indicated in the first row of each offspring sample in Table 2). According to this

Table 2 Chromosome segments from $D$. koepferae born by the males exhibiting anomalous spermatogenesis in the offspring samples of Table 1 ( $\mathrm{k} 0$ in to bIII). ? = unidentified hybrid recombinant

\begin{tabular}{|c|c|c|c|c|}
\hline $\begin{array}{l}\text { Introgressed } \\
\text { segment in the } \\
\text { hybrid mother }\end{array}$ & $\begin{array}{l}\text { Segment born } \\
\text { by offspring } \\
\text { males }\end{array}$ & $\begin{array}{l}\text { Size of the } \\
\text { segment (approx.) }\end{array}$ & $\begin{array}{l}\text { Type of abnormal } \\
\text { spermatogenesis }\end{array}$ & $\begin{array}{l}\text { Number of males } \\
\text { observed }\end{array}$ \\
\hline \multirow{7}{*}{$3 \mathrm{Ala}-\mathrm{H}$} & $3 \mathrm{Ala}-\mathrm{H}$ & 21.0 & $3 \mathrm{k}^{2}-5 \bar{g} \mathrm{w} / 2$ & 3 \\
\hline & 3B3-H & 16.9 & $3 \mathrm{k}^{2}-5 \mathrm{~g} w / 2$ & 1 \\
\hline & $3 A-D 4$ & 11.1 & $4 \mathrm{~m} / 3$ & 2 \\
\hline & 3 (E1-E2)-H & 9.6 & $4 \mathrm{~m} / 2$ & 2 \\
\hline & $3 \mathrm{E} 4-\mathrm{H}$ & 7.8 & $\mathrm{SS} / 1$ & 1 \\
\hline & $3 \mathrm{C} 1-\mathrm{E} 4$ & 7.5 & $4 \mathrm{~m} / 2$ & 1 \\
\hline & $3(\mathrm{~B} 3-\mathrm{B} 4)-\mathrm{D} 3$ & 6.7 & $4 \mathrm{~m} / 2$ & 2 \\
\hline \multirow[t]{3}{*}{$3 \mathrm{C} 36-\mathrm{H}$} & $3 \mathrm{C} 3-\mathrm{H}$ & 13.4 & $3 \mathrm{k}^{2}-5 \overline{\mathrm{g}} \mathrm{w} / 1$ & 9 \\
\hline & 3D5-H & 10.5 & $4 \mathrm{~m} / 2$ & 2 \\
\hline & $3 \mathrm{C} 3-\mathrm{F} 4$ & 9.7 & $4 \mathrm{~m} / 2$ & 1 \\
\hline \multirow[t]{3}{*}{$3 \mathrm{Ala}-\mathrm{E} 2 \mathrm{f}$} & $3 \mathrm{~A}-\mathrm{E} 2$ & 12.4 & $3 \mathrm{k}^{2}-5 \mathrm{~g} \mathrm{w} / 1$ & 8 \\
\hline & $3 A-(C 5-D 2)$ & 9.5 & $4 \mathrm{~m} / 2$ & 3 \\
\hline & $?$ & - & $4 \mathrm{~m} / 2$ & 1 \\
\hline \multirow[t]{2}{*}{$3 \mathrm{Al} a-\mathrm{D} 1 \mathrm{~b}$} & $3 A-(C 5-D 1)$ & 9.1 & $4 \mathrm{~m} / 2$ & 10 \\
\hline & $3 A-C 3$ & 8.2 & $\mathrm{SS} / 1$ & 2 \\
\hline $3 E 1 e-G 3 c$ & 3(E1-E2)-G3 & 7.2 & $\mathrm{SS} / 2$ & 12 \\
\hline $3 C 5 d-F 2 a$ & $3 \mathrm{C} 5-(\mathrm{F} 1-\mathrm{F} 2)$ & 6.6 & $4 \mathrm{~m} / 2$ & 11 \\
\hline $3 \mathrm{~A} 1 \mathrm{a}-\mathrm{C} 1 \mathrm{c}$ & $3 \mathrm{~A}-\mathrm{C} 1$ & 6.6 & $\mathrm{SS} / 1$ & 3 \\
\hline \multirow{2}{*}{$3 \mathrm{C} 1 \mathrm{e}-\mathrm{E} 2 \mathrm{f}$} & $3 \mathrm{C} 1-\mathrm{E} 2$ & 5.7 & $4 \mathrm{~m} / 2$ & 11 \\
\hline & $3 \mathrm{C} 1-\mathrm{D} 4$ & 4.4 & $\mathrm{SS} / 1$ & 1 \\
\hline 3D1b-E4d & $3 \mathrm{D} 1-\mathrm{E} 4$ & 4.4 & $\mathrm{SS} / 1$ & 12 \\
\hline \multirow[t]{7}{*}{$4 \mathrm{Ala}-\mathrm{H}$} & $4 \mathrm{~A} 1-\mathrm{H}$ & 16.8 & $3 k^{2}-5 \bar{g} w / 2$ & 5 \\
\hline & $4 \mathrm{D} 1-\mathrm{H}$ & 10.5 & $4 \mathrm{~m} / 3$ & 2 \\
\hline & $4 \mathrm{E} 1-\mathrm{H}$ & 8.2 & $4 \mathrm{~m} / 2$ & 1 \\
\hline & $4 \mathrm{~A}-\mathrm{D} 3$ & 7.8 & $4 \mathrm{~m} / 2$ & 1 \\
\hline & $4 C 2-(F 1-F 2)$ & 7.4 & $4 \mathrm{~m} / 2$ & 1 \\
\hline & $4 \mathrm{E} 4-\mathrm{H}$ & 6.3 & SS/2 & 1 \\
\hline & $4 \mathrm{~F} 2-\mathrm{H}$ & 4.5 & $\mathrm{SS} / 1$ & 1 \\
\hline \multirow[t]{3}{*}{$4 B 2 c-F 4 f$} & $4 \mathrm{~B} 2-\mathrm{F} 4$ & 10.7 & $3 \mathrm{k}^{2}-5 \overline{\mathrm{g} w} / 1$ & 9 \\
\hline & $4 \mathrm{~B} 2-(\mathrm{E} 2-\mathrm{E} 3)$ & 7.0 & $4 \mathrm{~m} / 2$ & 2 \\
\hline & 4E1-F4 & 5.3 & $\mathrm{SS} / 2$ & 1 \\
\hline 4D3b-H & $4 \mathrm{D} 3-\mathrm{H}$ & 9.4 & $4 \mathrm{~m} / 2$ & 12 \\
\hline $4 \mathrm{~F} 1 \mathrm{c}-\mathrm{H}$ & $4 \mathrm{~F} 1-\mathrm{H}$ & 5.0 & $\mathrm{SS} / 2$ & 12 \\
\hline $4 \mathrm{E} 3 \mathrm{f}-\mathrm{G} 2 \mathrm{a}$ & $4(\mathrm{E} 3-\mathrm{E} 4)-(\mathrm{G} 1-\mathrm{G} 2)$ & 4.3 & $\mathrm{SS} / 1$ & 12 \\
\hline $4 \mathrm{~F} 4 \mathrm{a}-\mathrm{H}$ & $4 \mathrm{~F} 4-\mathrm{H}$ & 3.6 & $\mathrm{SS} / 1$ & 1 \\
\hline
\end{tabular}


finding, it should be possible to characterize the effect on spermatogenesis of a given introgressed chromosome segment by simply identifying the most aberrant type of spermatogenesis found in the offspring of the corresponding hybrid mother (using Table 1 data, Spearman's rank correlation between maximum abnormality and segment size for chromosome 3 and 4 would be $r_{\mathrm{s}}=0.83$ and $r_{\mathrm{s}}=0.99$, respectively, both significant at the 0.5 per cent level).
The results of this procedure are shown in Table 3 , for several hybrids resulting from the introgression of separate segments of chromosomes 3,4 , and 5 from $D$. koepferae into $D$. buzzatii (strain b0), and, reciprocally, from $D$. buzzatii into $D$. koepferae (only for segments of chromosome 3 and 4). When no aberrant types were observed, the effect on spermatogenesis was considered as 'fertile type' $(\mathrm{F})$. As before, 30 male offspring were dissected, in each of at least two

Table 3 Effect of the introgression of separate chromosome segments on spermatogenesis. When no aberrant types were observed, the effect on spermatogenesis was considered as 'fertile type' $(F)$

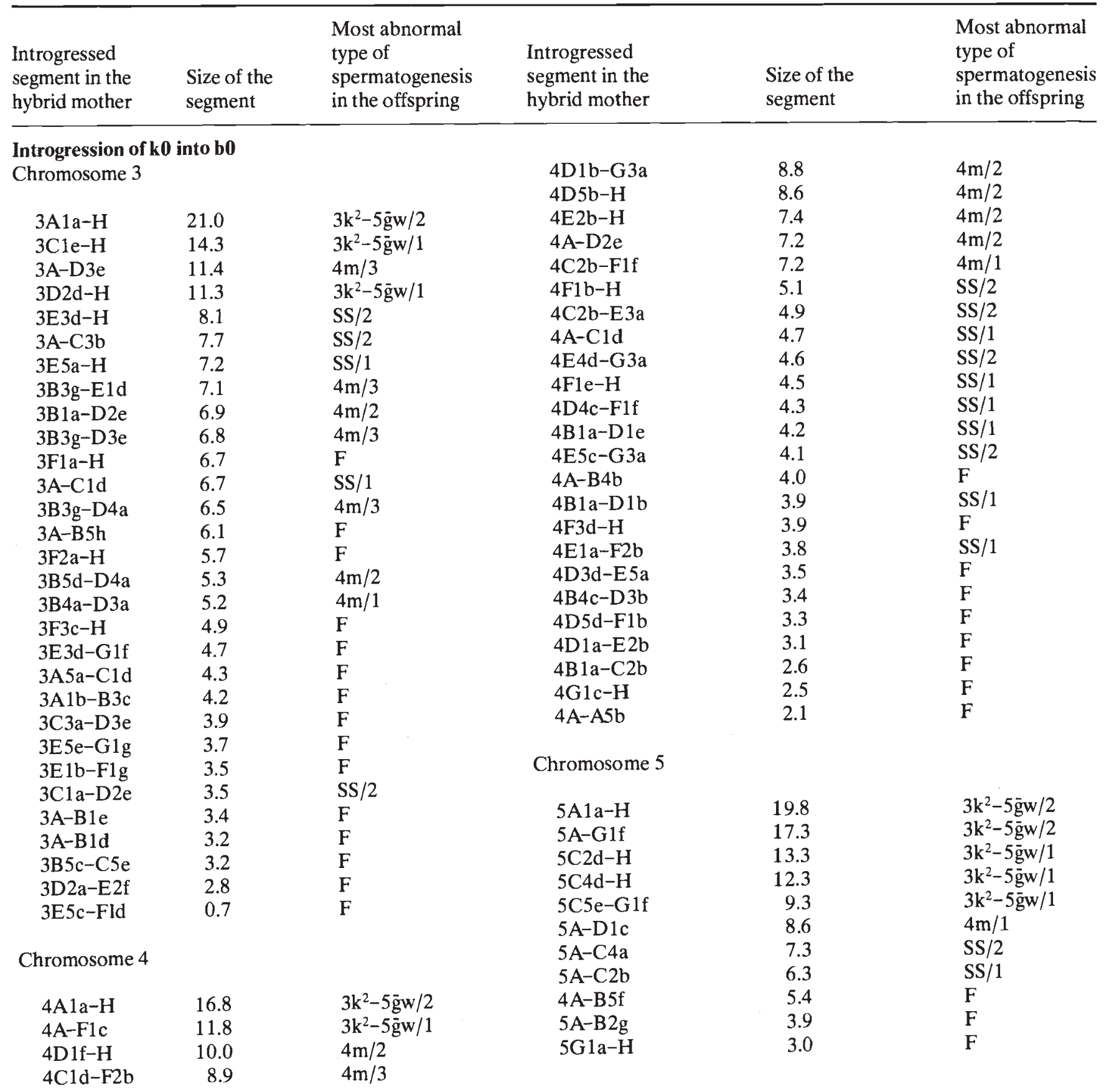


Table 3 Continued.

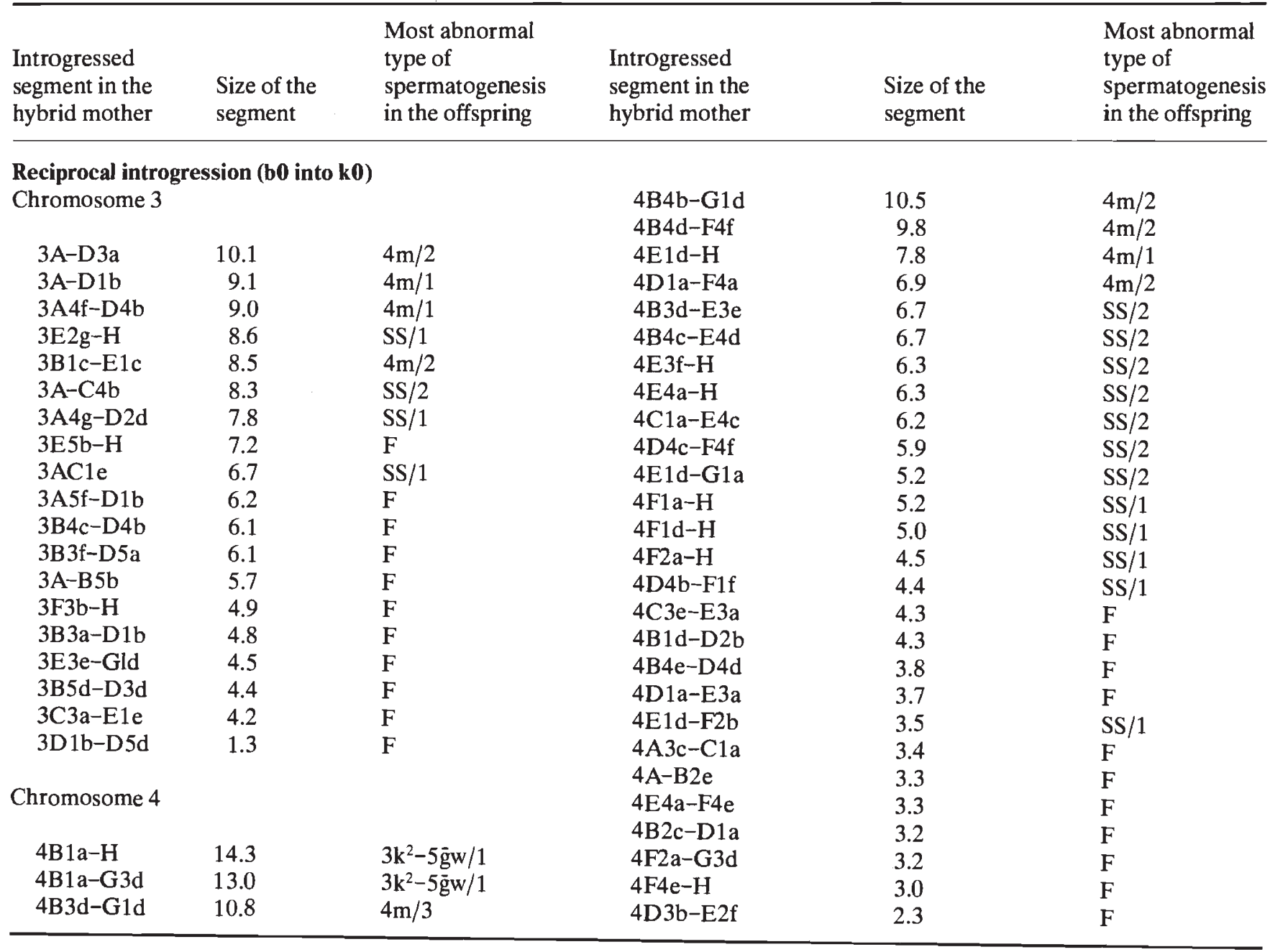

replicate crossings. In general, the association between segment size and degree of abnormality in spermatogenesis is manifest in all the different introgressive hybridizations $\left(r_{\mathrm{s}}=0.78, r_{\mathrm{s}}=0.94\right.$, and $r_{\mathrm{s}}=0.98$, for the introgression of segments of either chromosome 3 , 4 , or 5 from $\mathrm{k} 0$ into $\mathrm{b} 0$, respectively; $r_{\mathrm{s}}=0.87$ and $r_{\mathrm{s}}=0.96$, for the introgression of segments of either chromosome 3 or 4 from b0 into $\mathrm{k} 0$; all of them significant at the 0.1 per cent level), although some few interesting anomalies can also be found, similar to those in Table 2, and recognized here by the inclusion of a relatively more abnormal type of spermatogenesis within a series of less abormal types. This important question of the apparently heterogeneous distribution of the underlying genetic factors is best illustrated in Table 4, which shows the sizes of introgressed segments corresponding to the different spermatogenesis phenotypes, taken from Tables 2 and 3 , in each of three chromosomal regions: telomeric or distal (including the telomere of the chromosome), central (including the central cytological intervals D3, D4, and D5), and centromeric or proximal (including the centromere of the chromosome). In so far as the experimental error (in assessing the type of spermatogenesis and the length of the chromosome segment) is negligible, we may conclude that in our chromosome specimens the central region of chromosome 3 , both in $D$. koepferae and $D$. buzzatii, has apparently a larger 'density' of sterility factors than either the telomeric or the centromeric region (the sizes giving rise to the different spermatogenesis phenotypes are always smaller in the central region; $P=0.001$, according to a simple sign test, performed after comparing median scores of the different chromosomal regions for each type of spermatogenesis in Table 4). On the contrary, chromosome 4 is rather homogeneous $(P=0.226)$. Compared with chromosome 3 , the 'density' of sterility factors seems to be larger in chromosome 4 for the telomeric and centromeric regions $(P=0.031$ and $\mathrm{P}=0.016$, respectively) but smaller for the central region $(P=0.031)$. 
Table 4 Sizes of introgressed segments corresponding to the different spermatogenesis phenotypes in each of three chromosomal regions: telomeric (including the telomere of the chromosome), central (including the central cytological intervals D3, D4, and D5), and centromeric (including the centromere of the chromosome)

\begin{tabular}{|c|c|c|c|c|c|c|}
\hline \multirow{2}{*}{$\begin{array}{l}\text { Type of } \\
\text { spermatogenesis }\end{array}$} & \multicolumn{3}{|c|}{ Chromosome 3} & \multicolumn{3}{|c|}{ Chromosome 4} \\
\hline & Telomeric & Central & Centromeric & Telomeric & Central & Centromeric \\
\hline \multicolumn{7}{|l|}{ D. koepferae } \\
\hline $\mathrm{F}$ & $<6.1$ & $<2.8$ & $<6.7$ & $<4.0$ & $<3.5$ & $<3.9$ \\
\hline $\mathrm{SS} / 1$ & $6.6-6.7$ & 4.4 & 7.2 & 4.7 & - & 4.5 \\
\hline $\mathrm{SS} / 2$ & 7.7 & - & 8.1 & - & $4.9-5.3$ & $5.0-6.3$ \\
\hline $4 \mathrm{~m} / 1$ & - & - & - & - & 7.2 & - \\
\hline $4 \mathrm{~m} / 2$ & 9.1 & $5.7-6.6$ & $9.6-10.5$ & $7.2-7.8$ & 8.8 & $7.4-10.0$ \\
\hline $4 \mathrm{~m} / 3$ & 11.4 & 7.1 & - & - & 8.9 & 10.5 \\
\hline $3 \mathrm{k}^{2}-5 \mathrm{~g} \mathrm{w} / 1$ & 12.4 & - & $11.3-14.3$ & 11.8 & 10.7 & - \\
\hline $3 k^{2}-5 \mathrm{~g} w / 2$ & $21.0^{*}$ & $21.0^{*}$ & $16.9-21.0^{*}$ & $16.8^{*}$ & $16.8^{*}$ & $16.8^{*}$ \\
\hline \multicolumn{7}{|l|}{ D. buzzatii } \\
\hline $\mathrm{F}$ & $<5.7$ & $<4.2$ & $<7.2$ & $<3.3$ & $<4.3$ & $<3.0$ \\
\hline $\mathrm{SS} / 1$ & 6.7 & - & 8.6 & - & - & $4.5-5.2$ \\
\hline $\mathrm{SS} / 2$ & 8.3 & - & - & - & $6.2-6.7$ & 6.3 \\
\hline $4 \mathrm{~m} / 1$ & 9.1 & - & - & - & - & 7.8 \\
\hline $4 \mathrm{~m} / 2$ & 10.1 & 8.5 & - & - & $6.9-10.5$ & - \\
\hline $4 \mathrm{~m} / 3$ & - & - & - & - & 10.8 & - \\
\hline $3 \mathrm{k}^{2}-5 \bar{g} \mathrm{w} / 1$ & - & - & - & - & 13.0 & 14.3 \\
\hline $3 \mathrm{k}^{2}-5 \mathrm{~g} w / 2$ & - & - & - & - & - & - \\
\hline
\end{tabular}

*Whole chromosome.

Finally, the 'density' appears to be larger in $D$. koepferae than in $D$. buzzatii chromosomes $(P=0.028)$. These conclusions must be approached with caution because, only one specimen of each chromosome has been analysed to date, although a more extensive survey, where only fertility versus sterility was studied, is consistent with this pattern (Naveira \& Fontdevila, 1990).

It must be clearly understood that the general rule stated in our former publication (Naveira \& Fontdevila, $1986)$ is still valid: any region of chromosome 3 or 4 of $D$. koepferae (strain $\mathrm{k} 0$ ), if sufficiently small, can be introgressed into $D$. buzzatii without disturbing spermatogenesis to the point of preventing hybrid males from leaving at least some offspring (Table 3 ). When the size of the introgressed segment is increased, absolute sterility ensues ('minimum size effect'), and the abnormalities in spermatogenesis that underlie this sterility are also increasingly severe. The same is true for chromosome 4 of $D$. buzzatii b0. However, in chromosome 3 of this strain we have found what appears to be a major gene for hybrid sterility, the only one discovered until now on the autosomes of either species. We have mapped this factor in the interval 3E1e-E1h of $D$. buzzatii b0 (Naveira \& Fontdevila, 1991), which causes sterility by itself when intro- gressed into $D$. koepferae. The abnormalities in spermatogenesis that it causes do not correspond exactly to any of the types we have described so far. Spermatid nuclei look like $3 \mathrm{k}^{2}-5 \bar{g} \mathbf{w} / 2$ (very small chromatin dots lagging behind in the cyst tail regions), but the cysts are generally abundant and well elongated, and the testes are never atrophied. Except for this sterility factor, chromosome 3 of $D$. buzzatii is similar to the other autosomes in terms of its determination of hybrid male sterility ('minimum size effect'), although the number of different chromosome segments analysed is rather limited because only segments that do not contain the major sterility factor were valid for our analysis. The possibility of detecting types of sterility that do not conform to the patterns defined in the Appendix, e.g. that produced by this major sterility factor, or those found in $D$. buzzatii controls, is an indication that the similarities between the effects of different introgressed segments are not an artifact of the method. Many different departures from normal spermatogenesis could conceivably exist. The striking fact is that introgression appears to be tightly linked to the production of only a particular subset of all possible alterations.

As a final demonstration of the cumulative and interchangeable effects of the minor sterility factors 
distributed across the autosomes, we performed a series of crosses between introgression lines that contain segments with previously identified effects on hybrid male fertility. Thus we were able to combine two segments of known separate effect on spermatogenesis in a single male, and observe the effects of their simultaneous introgression (Table 5). The combination of two segments nearly always gives rise to a more severe disturbance than the introgression of each segment separately. Futhermore, two segments that separately allow fertility can cause sterility when simultaneously introgressed in the same male. The general association between the added size of each pair of segments and the degree of abnormality in the spermatogenesis is also quite clearly displayed by this experi-

Table 5 Comparison of the effect on spermatogenesis of separate introgessed segments (Table 3) with that of the simultaneous introgression of pair-wise combinations. The effect on spermatogenesis is given by the most aberrant spermatogenesis type observed in the offspring of the corresponding hybrid mother (segments from $\mathrm{k} 0$ into b0)

\begin{tabular}{|c|c|c|c|}
\hline $\begin{array}{l}\text { Introgressed } \\
\text { segments }\end{array}$ & Size & $\begin{array}{l}\text { Separate } \\
\text { effect on } \\
\text { spermatogenesis }\end{array}$ & $\begin{array}{l}\text { Combined } \\
\text { effect on } \\
\text { spermatogenesis }\end{array}$ \\
\hline $3 A-D 3 e$ & 11.4 & $4 \mathrm{~m} / 3$ & \\
\hline $3 \mathrm{~F} 1 \mathrm{a}-\mathrm{H}$ & 6.7 & $\mathrm{~F}$ & $3 k^{2}-5 g w / 2$ \\
\hline $3 \mathrm{E} 3 \mathrm{~d}-\mathrm{H}$ & 8.1 & $\mathrm{SS} / 2$ & \\
\hline $3 \mathrm{~A}-\mathrm{B} 1 \mathrm{e}$ & 3.4 & $\mathrm{~F}$ & $4 \mathrm{~m} / 2$ \\
\hline $3 \mathrm{E} 5 \mathrm{e}-\mathrm{G} 1 \mathrm{~g}$ & 3.7 & $\mathrm{~F}$ & \\
\hline $3 A-B 1 d$ & 3.2 & $\mathrm{~F}$ & $\mathrm{SS} / 1$ \\
\hline $4 \mathrm{E} 4 \mathrm{~d}-\mathrm{G} 3 \mathrm{a}$ & 4.6 & $\mathrm{SS} / 2$ & \\
\hline $4 \mathrm{~A}-\mathrm{B} 4 \mathrm{~b}$ & 4.0 & $\mathrm{~F}$ & $4 \mathrm{~m} / 2$ \\
\hline 4B1a-D1e & 4.2 & SS/1 & \\
\hline $4 \mathrm{G} 1 \mathrm{c}-\mathrm{H}$ & 2.5 & $\mathrm{~F}$ & $4 \mathrm{~m} / 1$ \\
\hline $3 F 3 c-H$ & 4.9 & $\mathrm{~F}$ & \\
\hline $4 \mathrm{C} 2 \mathrm{~b}-\mathrm{F} 1 \mathrm{f}$ & 7.2 & $4 \mathrm{~m} / 1$ & $3 \mathrm{k}^{2}-5 \bar{g} \mathrm{w} / 1$ \\
\hline $3 F 3 c-H$ & 4.9 & $\mathrm{~F}$ & \\
\hline $4 \mathrm{E} 2 \mathrm{~b}-\mathrm{H}$ & 7.4 & $4 \mathrm{~m} / 2$ & $4 \mathrm{~m} / 3$ \\
\hline $3 \mathrm{~F} 2 \mathrm{a}-\mathrm{H}$ & 5.7 & $\mathrm{~F}$ & \\
\hline $4 \mathrm{~A}-\mathrm{A} 5 \mathrm{~b}$ & 2.1 & $F$ & $4 \mathrm{~m} / 1$ \\
\hline 3A-Ble & 3.4 & $\mathrm{~F}$ & \\
\hline $4 B 4 c-D 3 b$ & 3.4 & $\mathrm{~F}$ & $\mathrm{SS} / 1$ \\
\hline $3 \mathrm{~B} 5 \mathrm{~d}-\mathrm{D} 4 \mathrm{a}$ & 5.3 & $4 \mathrm{~m} / 2$ & \\
\hline 4F1b-H & 5.1 & $\begin{array}{l}\mathrm{SS} / 2 \\
\mathrm{SS} / 1\end{array}$ & $4 \mathrm{~m} / 3$ \\
\hline $\begin{array}{l}3 \mathrm{E} 5 \mathrm{a}-\mathrm{H} \\
5 \mathrm{~A}-\mathrm{B} 2 \mathrm{~g}\end{array}$ & $\begin{array}{l}7.2 \\
3.9\end{array}$ & $\begin{array}{l}\mathrm{SS} / 1 \\
\mathrm{~F}\end{array}$ & $\mathrm{SS} / 1$ \\
\hline $\begin{array}{l}5 \mathrm{~A}-\mathrm{B} 2 \mathrm{~g} \\
3 \mathrm{E} 5 \mathrm{c}-\mathrm{F} 1 \mathrm{~d}\end{array}$ & $\begin{array}{l}3.9 \\
0.7\end{array}$ & $\mathrm{~F}$ & \\
\hline $5 \mathrm{~A}-\mathrm{B} 5 \mathrm{f}$ & 5.4 & $F$ & $\mathrm{SS} / 1$ \\
\hline $3 \mathrm{~A} 1 \mathrm{a}-\mathrm{H}$ & 21.0 & $3 \mathrm{k}^{2}-5 \overline{\mathrm{g}} \mathrm{w} / 2$ & \\
\hline $4 \mathrm{~A} 1 \mathrm{a}-\mathrm{H}$ & 16.8 & $3 \mathrm{k}^{2}-5 \mathrm{~g} w / 2$ & $2 b / k$ \\
\hline $3 \mathrm{~A} 1 \mathrm{a}-\mathrm{H}$ & 21.0 & $3 \mathrm{k}^{2}-5 \mathrm{~g} w / 2$ & \\
\hline $5 \mathrm{Ala}-\mathrm{H}$ & 19.8 & $3 \mathrm{k}^{2}-5 \mathrm{~g} w / 2$ & $2 b / k$ \\
\hline
\end{tabular}

ment $\left(r_{\mathrm{s}}=0.86\right.$, significant at the 0.1 per cent level $)$, where for the first time the phenotype $2 b / k$, the most abnormal one, occurs (by the simultaneous introgression of two whole chromosomes from $D$. koepferae into D. buzzatii).

Most introgressed segments of chromosome X lead to hybrid male inviability (unpublished results). Among those that allow viability, the majority give rise to the most extreme type of hybrid male sterility $(2 b / k)$, with conspicuous atrophy of the testes. This is true for segments XB2a-D1b and XD4e-F1f, which represent only 5.8 and 3.8 per cent of the total haploid polytene karyotype, respectively. Other, less abnormal, patterns of hybrid male sterility have also been observed occasionally, probably corresponding to products of infrequent crossing over in the heterospecific region of the chromosome homologues. Some of these patterns are similar to those described for autosomes $(4 \mathrm{~m}$ or $\left.3 \mathrm{k}^{2}-5 \mathrm{~g} w\right)$, but others are definitely different, apparently being specific of $\mathrm{X}$ chromosome introgressions (H. Naveira, in preparation).

\section{Discussion}

Our results show that throughout the autosomes of $D$. buzzatii and $D$. koepferae there are many non-allelic, minor sterility genes, whose individual segregation cannot be recognized phenotypically, and which act cumulatively on the same characteristics of spermatogenesis, each contributing a small effect to their disturbance in the hybrid male. Accordingly, these genes should be considered as polygenes, and the type of sterility they bring about ('minimum size effect') should be designated as polygenic sterility. We can only speculate about the possible nature of these polygenes. In $D$. melanogaster there are certain types of mutation that bring about what is generally called 'chromosomal sterility' (Lifschytz \& Lindsley, 1974; Lindsley \& Tokuysau, 1980), which is not linked with segregational problems at meiosis. It is exhibited by mutants that consist of reciprocal and insertional $\mathrm{X}$-autosome translocations, and manifests a remarkable dependence on the size of the translocated chromosome segment, sterility most probably resulting from the interference with the asynchronous inactivation of the $\mathrm{X}$ and the autosomes in the primary spermatocytes (Lindsley \& Lifschytz, 1972). Something similar may occur in the hybrids between $D$. koepferae and $D$. buzzatii. The polygenes may simply correspond to elements involved in the inactivation of the autosomes; the whole autosome set being inactivated at the same time by a general cellular mechanisms. The timing of this inactivation could be different in $D$. koepferae and 
D. buzzatii. Thus, the increased severity of the abnormalities in spermatogenesis might correspond to an increased asynchronization in chromosome inactivation, brought about by larger introgressed segments. This hypothesis is problematic, because the $\mathrm{X}$ is also known to play an important role in hybrid inviability and female sterility (Charlesworth et al., 1987), neither of which is associated with asynchronous inactivation in spermatogenesis, although it is possible that slightly different mechanisms are involved in each case.

Another possibility is that sex determination in the germ line of the hybrids is affected by introgression. It is known that the $\mathrm{X} / \mathrm{A}$ ratio (X:autosomes) is the primary determinant of a regulatory cascade that controls both sex determination and dosage compensation in somatic cells (Gadagkar et al., 1982; Baker \& Belote, 1983), and sex determination in the germ line (Marsh \& Wieschaus, 1978; Cline, 1983; Cronmiller \& Cline, 1987). It is important to realize that partly different regulatory pathways are involved in sex determination in the germ line and the soma. Even $d a$ (daughterless) and Sxl (Sex-lethal), two genes common to both regulatory pathways, have different functions in the germ line and the soma (Cline, 1983; Schüpbach, 1985; Cronmiller \& Cline, 1987). Therefore, an X/A ratio could be seen to be correct by the soma but incorrect by the germ line. This possibility is supported by recent findings of multiple RNA-binding sites in the $S x l$ protein, each possibly binding independently of the others (Bandziulis et al., 1989). These germ-line specific functions, which are far from being completely understood, cast serious doubt on the validity of some recent attempts to test the hypothesis of hybrid sterility produced by an anomalous X/A ratio (Orr, 1989c), particularly given that in the germ line the expression of $S x l$ may be regulated by specific genes (Oliver et al., 1988). Even if this criticism could be disregarded, what Orr's experiments show is that in $F_{1}$ hybrids between $D$. melanogaster and D. simulans there must be other causes of hybrid sterility in addition to a disruption of the $\mathrm{X} / \mathrm{A}$ ratio, although the altered $\mathrm{X} / \mathrm{A}$ ratio can also be a cause. Little is known about the $\mathrm{X} / \mathrm{A}$ elements, i.e. the genes whose relative dose determines the $\mathrm{X} / \mathrm{A}$ signal. Until now, only two 'numerator elements' have been indentified in $D$. melanogaster, although several more apparently exist (Cline, 1988). Nothing is known, however, about the 'denominator elements', the factors that should be counted to give the denominator of the signal X/A. We think that the autosomal polygenes that bring about male sterility in our hybrids might indeed correspond to 'denominator elements', differentiated in D. koepferae and D. buzzatii. The differentiation between two species that causes the sterility of their hybrids could be brought about by an accumulation of compensatory changes in the $\mathrm{X}$ and the autosomes. The possibility of reproducing similar patterns of hybrid sterility after the introgression of either autosome or X chromosome segments is consistent with this hypothesis. Nevertheless, the observation of other patterns specifically associated with the introgression of $\mathrm{X}$ chromosome segments suggests that this chromosome may also play a role on its own, independently of its interaction with autosomal factors.

Many of the results on the genetic basis of hybrid sterility in other pairs of Drosophila species (cited in the Introduction), may have been produced by polygenes (chromosomal sterility, characterized by the minimum size effect) instead of major genes (genic sterility), as currently believed. This possibility cannot be ruled out because the size of the introgressed segments is generally unknown. The frequently disproportionate effects of the $\mathrm{X}$ chromosome on interspecific inviability or sterility, which have been interpreted as evidence in favour of the involvement of major genes in the determination of reproductive isolation (Charlesworth et al., 1987), are also consistent with the models of polygenic inheritance discussed above. Both for the hypothesis of abnormal chromosome inactivation in spermatocytes and abnormal sex determination in the germ line, it is sufficient to postulate a higher 'density' of sterility factors in the $\mathrm{X}$ than in the autosomes, which corresponds to the observation that in both systems the $\mathrm{X}$ is 'compared' with the whole autosome set. Then, the minimum size for hybrid sterility should be much smaller in the $\mathrm{X}$ than in the autosomes. This is indeed the case in the hybrids of $D$. buzzatii and $D$. koepferae (Naveira \& Fontdevila, 1986, 1991), and cannot be discarded in other hybrids where major genes of hybrid sterility have been mapped (Coyne \& Charlesworth, 1989), again, because the size of the introgressed chromosome segments is unknown. The extreme disturbance in spermatogenesis brought about by the introgression of relatively small $\mathrm{X}$ chromosome segments (described in this paper) is entirely consistent with this hypothesis of higher 'density' of sterility factors in this chromosome.

$D$. koepferae and $D$. buzzatii are two relatively old species (Nei's $D=0.73$, A. Sánchez \& A. Fontdevila, unpublished results). We do not know how the polygenic basis of their hybrid male sterility may have evolved, or how a similar type of sterility could be manifest in hybrids between younger species. There is no a priori reason to expect that this genetic basis evolves exactly at the same rate throughout the genome. Perhaps the first stages of speciation correspond to one or a few rapidly evolving chromosome segments, which contain localized polygenic sets that progressively expand to the rest of the genome by some 
kind of genome turnover (Flavell, 1982). On the other hand, it may be that the number of interacting polygenic loci (corresponding to potentially mutable genes) is far greater than the minimum number of actually mutated alleles that are necessary to bring about hybrid sterility. Even with equal mutation rates for all loci, some heterogeneity within and among chromosomes in the critical sizes for hybrid sterility is expected, particularly in hybridizations between close relatives. This might be the case in hybrids between the subspecies $D$. pseudoobscura Bogota and D. pseudoobscura USA $(D=0.194)$, where some large $\mathrm{X}$ chromosome segments allow sperm motility, whereas segments (possibly smaller) from other $\mathrm{X}$ chromosome regions do not (Orr, 1989a, 1989b; undetected recombination cannot be excluded in these studies, and therefore the actual size of the introgressed segments is unknown). Critical sizes for hybrid sterility should become smaller with time, as differentiation in the interacting polygenic sets linked to the $\mathrm{X}$ and the autosomes accumulates. This is in good agreement with Coyne \& Orr's (1989) data, which suggest a steady accumulation of polygenic variation. Accordingly, hybrids between closely related species should exhibit larger critical sizes than hybrids between more distantly related species, with the $\mathrm{X}$ chromosome always playing the most important role. This also agrees with the findings of Orr \& Coyne $(1989)$ in the $D$. virilis group, where the $\mathrm{X}$ alone has a discernible effect on postzygotic isolation between closely related species, whereas autosomes may also play a role in hybridizations between more distantly related species.

The importance of differentiation in balanced polygenic systems to bring about new species cannot be sufficiently emphasized. The analysis of spermatogenesis in Drosophila hybrids offers an excellent opportunity to study these phenomena. New experiments should be designed to understand how these minor genes work and evolve.

\section{Acknowledgements}

This work supported by grant number 0910/81, awarded to AF by the 'Comisión Asesora de Investigación Científica y Técnica', Spain, and a research scholarship awarded to HN from the 'Programa de Formación de Personal Investigador, Ministerio de Educación y Ciencia', Spain, that covered his personal salary and part of the research expenses.

\section{References}

BAKER, B. S. AND BELOTE, J. M. 1983. Sex determination and dosage compensation in Drosophila melanogaster. Ann.
Rev. Genet., 17, 345-397.

BANDZIULIS, R. J., SWANSON, M. S. AND DREYFUSS, G. 1989. RNAbinding proteins as developmental regulators. Genes Dev., 3, 431-437

Bock, I, R. 1984. Interspecific hybridization in the genus Drosopila. Evol. Biol., 18, 41-70.

CHARLESWORTH, B., COYNE, J. A. AND BARTON, N. H. 1987. The relative rates of evolution of sex chromosomes and autosomes. Am. Nat., 130, 113-146.

CLINE, T. w. 1983. Functioning of the genes daughterless $(d a)$ and sex-lethal $(S x l)$ in Drosophila germ cells. Genetics, 104, s16-17.

CLINE, T. w. 1988. Evidence that sisterless-a and sisterless-b are two of several discrete 'numerator elements' of the $\mathrm{X} / \mathrm{A}$ sex determination signal in Drosophila that switch $\mathrm{Sxl}$ between two alternative stable expression states. Genetics, 119, 829-862.

COYNE, J. A. 1984. Genetic basis of male sterility in hybrids between two closely related species of Drosophila. Proc. Natl. Acad. Sci, USA, 81, 4444-4447.

COYNE, J. A. AND CHARLESWORTH, B. 1989. Genetic analysis of $\mathrm{X}$-linked sterility in hybrids between three sibling species of Drosophila. Heredity, 62, 97-106.

COYNE, J. A. AND KREITMAN, M. 1986. Evolutionary genetics of two sibling species of Drosophila, D. simulans and $D$. mauritiana. Evolution, 40, 673-691.

COYNE, J. A. AND ORR, H. A. 1989. Patterns of speciation in Drosophila. Evolution, 43, 362-381.

CRONMILlER, C. AND Cline, T. W. 1987, the Drosophila sex determination gene daughterless has different functions in the germ line versus the soma. Cell, 48, 479-487.

DOBZHANSKy, TH. 1936. Studies on hybrid sterility. II. Localization of sterility factors in Drosophila pseudoobscura hybrids. Genetics, 21, 113-135.

FLAVELL, R. B. 1982. Sequence amplification, deletion and rearrangement: major sources of variation during species divergence. In: Dover, G. A. and Flavell, R. B. (eds) Genome Evolution, Academic Press, New York.

fontdeVila, A.. PLA, C., haSSON, E., WASSERman, M., SANChez, A., NAVEIRA, H. AND RUIZ, A. 1988. Drosophila koepferae: A new number of the Drosophila serido (Diptera: Drosophilidae) superspecies taxon. Ann. Entomol. Soc. Am., 81, 380-385.

GADAGKAR, R., NANJUNDIAH, V., JOSHI, N. V. AND CHANDRA, H. S. 1982. Dosage compensation and sex determination in Drosophila: Mechanism of measurements of the X/A ratio. J. Biosci., 4, 337-360.

HALDANE, J. B. S. 1922. Sex ratio and unisexual sterility in hybrid animals. J. Genet., 12, 101-109.

LABRADOR, M., NAVEIRA, H. AND FONTDEVILA, A. 1990. Genetic mapping of the $A d h$ locus in the repleta group of Drosophila by 'in situ' hybridization. J. Hered., 81, 83-86.

LIFSCHYTZ, E. AND LiNDSLEY, D. L. 1974. Sex chromosome activation during spermatogenesis. Genetics, 78, 323-331.

LIFSCHYTZ, E. AND MEYER, G. F. 1977. Characterization of male meiotic sterile mutations in Drosophila melanogaster. Chromosoma, 64, 371-392.

LINDSLEY, D. L. AND LIFSCHYTZ, E. 1972. The genetic control of spermatogenesis in Drosophila. In: Beatty, R. A. and 
Glueckson-Waelsch, S. (eds), The Genetics of the Spermatozoon, University of Edinburgh Press, Edinburgh, 203-222.

LINDSLEY, D. L. AND TOKUYASU, K. T. 1980. Spermatogenesis. In: Ashburner, M. and Wright, T. R. F. (eds), The Genetics and Biology of Drosophila, Vol. 2d, Academic Press, New York, 225-294.

MARSH, J. L. AND WIESCHAUS, E. 1978. Is sex determination in germ line and soma controlled by separate genetic mechanisms? Nature, 272, 249-251.

NAVEIRA, H. AND FONTDEVILA, A. 1986. The evolutionary history of Drosophila buzzatii. XII. The genetic basis of sterility in hybrids between $D$. buzzatii and its sibling $D$. serido from Argentina. Genetics, 114, 841-857.

NAVEIRA, H. AND FONTDEVILA, A. 1991. The evolutionary history of Drosophila buzzatii. XXII. Chromosomal and genic sterility in male hybrids of Drosophila buzzatii and Drosophila koeferae. Heredity, 66, 233-240.

NAVEIRA, H., HAUSCHTECK-JUNGEN, E. AND FONTDEVILA, A. 1984. Spermiogenesis of inversion heterozygotes in backcross hybrids between Drosophila buzzatii and D. serido. Genetica, 65, 205-214.

NAVEIRA, H., HAUSCHTECK-JUNGEN, E. AND FONTDEVLA, A. 1989. The evolultionary history of Drosophila buzzatii. XV. Meiosis of inversion heterozygotes in backcross hybrids between $D$. buzzatii and its sibling $D$. koepferae. Genome, 32, 262-270.

NAVEIRA, H., PLA, C. AND FONTDEVILA, A. 1986. The evolutionary history of Drosophila buzzatii. XI. A new method for cytogenetic localization based on asynapsis of polytene chromosomes in interspecific hybrids of Drosophila. Genetica, 71, 199-212.

OLIVER, B., PERrimon, N. AND Mahowald, A. P. 1988. Genetic evidence that the sans fille locus is involved in Drosophila sex determination. Genetics, 120, 159-171.

ORR, H. A. 1987. Genetics of male and female sterility in hybrids of Drosophila pseudoobscura and D. persimilis. Genetics, 116, 555-563.

ORR, H. A. 1989a. Genetics of sterility in hybrids between two subspecies of Drosophila. Evolution, 43, 180-189.

ORR, H. A. 1989 b. Localization of genes causing postzygotic isolation in two hybridizations involving Drosophila pseudoobscura. Heredity, 63, 231-237.

ORR, H. A. 1989 c. Does postzygotic isolation result from improper dosage compensation? Genetics, 122, 891-894.

ORR, H. A. AND COYNE, J. A. 1989. The genetics of postzygotic isolation in the Drosophila virilis group. Genetics, 121, 527-537.

PONTECORVO, G. 1943. Hybrid sterility in artificially produced recombinants between Drosophila melanogaster and $D$. simulans. Proc. R. Soc. Edinb. Sect. B., 61, 385-397.

Ruiz, A., FONTDEVILA, A. AND WASSERMAN, M. 1982. The evolutionary history of Drosophila buzzatii. III. Cytogenetic relationships between two sibling species of the buzzatii cluster. Genetics, 101, 503-518.

SCHÜPBACH, T. 1985. Normal female germ cell differentiation requires the female $\mathrm{X}$-chromosome to autosome ratio and expression of Sex-lethal in Drosophila melanogaster. Genetics, 109, 529-548.

VIGNEAULT, G. AND zouros, E. 1986. The genetics of asymmetrical male sterility in Drosophila mojavensis and Drosophila arizonensis hybrids: Interactions between the Y-chromosome and autosomes. Evolution, 40, 1160-1170.

WHARTON, L. T. 1942. Analysis of the repleta group of Drosophila. Univ. Texas Publ., 4228, 23-52.

zOUROS, E., LOFDHAL, K. AND MARTIN, P. A. 1988. Male hybrid sterility in Drosophila: Interactions between autosomes and sex chromosomes in crosses of $D$. mojavensis and $D$. arizonensis. Evolution, 42, 1321-1331.

\section{Appendix}

Class intervals in spermatogenesis of hybrid males.

\section{Fertile (F)}

Arbitrary value: 1 .

Meiosis: normal.

Preindividualization stages: numerous, wellelongated cysts ( 50 per testis) with bundles of about 64 well-elongated spermatid nuclei in their head region. Non-elongated nuclei are seldom observed in the tail region of the cyst. The chromatin is generally uniformly distributed.

Individualization stage: perfectly individualized spermatids.

Coiling stage: sperm nuclei are held in intimate apposition, aligned in parallel and forming a dense chromatin bundle with individual sperm tails coiled around (Fig. A1a).

Sperm release: seminal vesicles are gross, full of huge bundles of a few thousand motile sperm.

Testis: normal in appearance and in size (1980-2600 $\mu \mathrm{m}$ in length, Fig. A2a).

\section{Semisterile class 1 (SS/1, intermediate between F and $S S / 2)$}

Arbitrary value: 2 .

Meiosis: normal.

Preindividualization and individualization stages: same as in fertiles.

Coiling stage: it seems to proceed correctly but sperm are not always transferred to the seminal vesicle (probably because of difficulties in the entrapment stage), which results in an accumulation of degenerating coiled sperm bundles in the basal testicular region (Fig. A1b), just before the constriction that marks the entry to the seminal vesicle.

Sperm release: seminal vesicles are relatively thin, with few, generally motile sperm.

Testis: normal size, but they exhibit a typical engrossment in the basal testicular region, which becomes more pronounced as the males become older (Fig. A2b). 

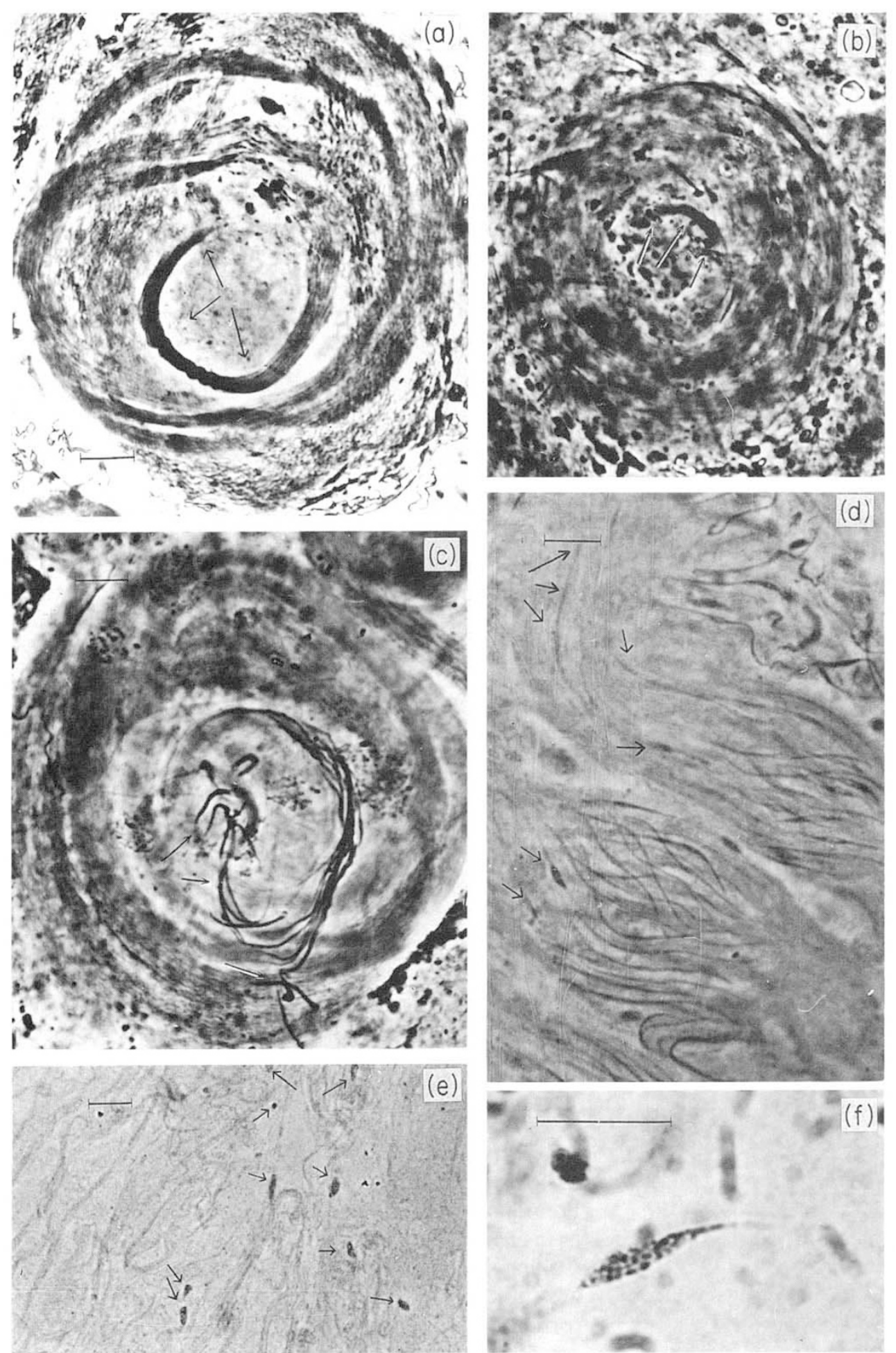

Fig. A1 Different types of spermatogenesis in hybrid males. Orcein staining. (a) Coiling stage in a fertile male, showing the intimate apposition of the nuclei, all aligned in parallel fashion, forming a dense chromatin bundle (arrows). (b) Degenerating coiled sperm bundle in a semisterile male, with chromatin bundle at the centre (arrows). (c) Coiling stage in a sterile male of the type $4 \mathrm{~m} / 1$, showing scattered sperm nuclei (arrows) at the centre of the coiled tails. (d) Spermatid nuclei of elongating cysts in a sterile male of the type $4 \mathrm{~m} / 2$, nearly all lying at different levels in the head region, without tight apposition, some lagging behind with incomplete elongation (arrows). (e) Unelongated nuclei (arrows) in the tail region of elongating cysts in sterile males of the type
$3 \mathrm{k}^{2}-5 \overline{\mathrm{g}} w / 1$. (f) Detail of one nucleus in picture 1e, showing a canoe-like shape and abnormal chromatin condensation (dots).
$\mathrm{Bar}=10$ $\mathrm{Bar}=10 \mu \mathrm{m}$. 

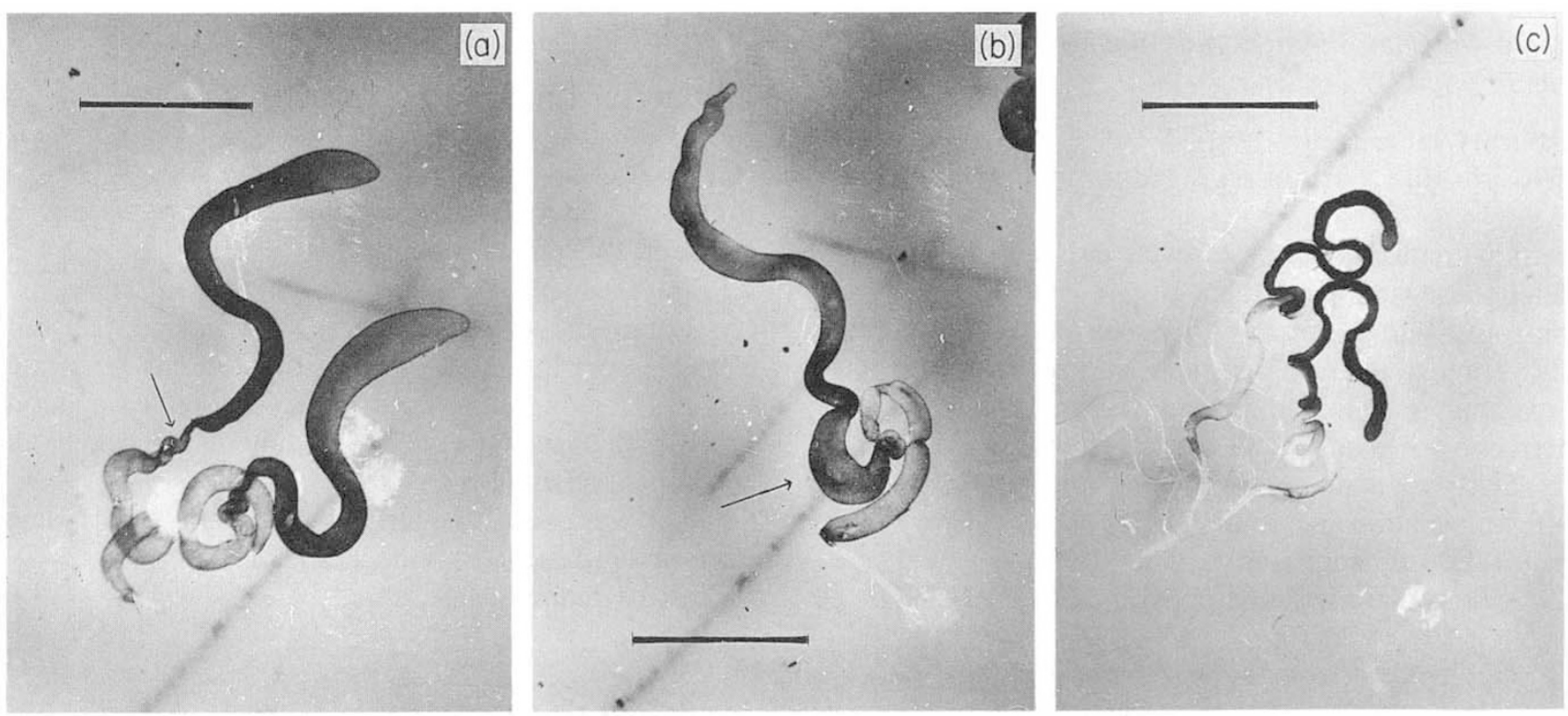

Fig. A2 Testes and seminal vesicles in hybrid males. (a) Fertile male, showing the constriction that marks the entry to the seminal vesicle (arrow). (b) Semisterile male, showing the typical engrossment in the basal testicular region (arrow). (c) Sterile male of the most abnormal type, $2 \mathrm{~b} / \mathrm{k}$, showing clearly atrophied testes. $\mathrm{Bar}=1 \mathrm{~mm}$.

\section{Semisterile class 2 (SS/2)}

Arbitrary value: 3 .

Meiosis: normal.

Preindividualization stages: same as in fertiles.

Individualization: some spermatid nuclei (less than 80 per cent) are swept by the cystic bulge, thus giving rise to anucleated spermatids. Coiled sperm bundles occupy most of the testis and not only its basal region, which appears greatly engrossed by the accumulation of degenerating coils. Seminal vesicles are extremely thin, most often with few or no motile sperm at all.

\section{Sterile $4 m$ class $1 / 4 m / 1$, intermediate between SS/2 and $4 m / 2$ )}

Arbritrary value: 4 .

Meiosis: normal.

Preindividualization stages: similar to fertiles, except for some nuclei being misplaced, lagging behind the bundle in the head region. All the nuclei seem to be normally elongated but they are often not uniformly stained, which suggests an irregular condensation of their chromatin.

Individualization stage: most of the spermatid nuclei (more than 80 per cent) are swept by the cystic bulge.

Coiling stage: it is always abnormal but it can be very abundant. The few sperm that are successfully individualized in each bundle now appear more or less scat- tered, and are longer aligned in parallel, in the centre of each coiled bundle (Fig. A1c).

Sperm release: seminal vesicles are thin, containing some degraded products of the germ line and sometimes even sperm, which is always immotile.

Testis: normal in size and appearance, frequently with a slight engrossment at the entry to the seminal vesicle.

\section{Sterile $4 m$ class $(4 m / 2)$}

Arbitrary value: 5 .

Meiosis: normal.

Preindividualization stage: some spermatid nuclei $(40$ per cent at most) lie in the cyst tail region, but all the nuclei in the head region are also misplaced and lie at different levels instead of the tight apposition characterized in normal males (Fig. A1). The elongation of the nuclei is always incomplete and they do not stain uniformly.

Individualization stage: less than 10 per cent of the nuclei stay in the head region after individualization, and their aspect is nearly always abnormal, being reduced to simple chromatin dots.

Coiling stage: it really never takes place, although sperm tails manifest a tendency to coil in the basal testicular region.

Sperm release: seminal vesicles are gross, full of degraded products of germ line material but no sperm at all.

Testis: generally normal in size and appearance. 
Sterile $4 m$ class $3(4 m / 3$, intermediate between $4 m / 2$ and $\left.3 k^{2}-5 \dot{g} w / 1\right)$

Arbitrary value: 6 .

Meiosis: some aberrant segregations in anaphase I and II.

Preindividualization stage: cysts are always incompletely elongated (less than 70 per cent of $D$. buzzatii controls), with a number of nuclei in the tail region (always more than 40 per cent), and nearly all the few remaining nuclei in the head region lagging behind their normal position, all incompletely elongated and irregularly stained.

Individualization and coiling stages do not occur.

Sperm release: same as for $4 \mathrm{~m} / 2$.

Testis: normal in size and appearance.

\section{Sterile $3 k^{2}-5 \bar{g} w$ class $1\left(3 k^{2}-5 \bar{g} w / 1\right)$}

Arbitrary value: 7 .

Meiosis: precocious separation of sister chromatids and aberrant segregations in anaphase I. Chromosomes seperated into their constituent chromatids in metaphase II. Aberrant segregations and multipolar spindles in anaphase II.

Preindividualization stages: always incompletely elongated cysts (30-40 per cent of $D$. buzzatii controls), but generally well formed and each perfectly differentiated (no coalescence). The number of nuclei per cyst varies considerably, as a consequence of the severe anomalies during meiosis. All the spermatid nuclei lie in the tail cyst region, without any preferential location and scattered over the elongated cyst. In addition, they are incompletely elongated, with different characteristic shapes (canoe-like, dot-like, etc.) obeying to aberrant elongation processes, and abnormal chromatin condensation (Fig. A1e and f).
Individualization and coiling stages do not occur. Sperm release: same as for $4 \mathrm{~m} / 2$.

Testis: normal in size and appearance.

\section{Sterile $3 k^{2}-5 \bar{g} w$ class $2\left(3 k^{2}-5 \bar{g} w / 2\right.$, intermediate}

between $3 k^{2}-5 \bar{g} w / 1$ and $\left.2 b / k\right)$

Arbitrary value: 8 .

Cysts often show coalescence, are generally scarce, and elongate very little. All the spermatid nuclei lie in the cyst tail region, sometimes with aberrant elongation processes but most frequently with no elongation at all and appear as small chromatin dots.

Seminal vesicles are thin and contain only some degraded products from the germ line.

Testes are frequently atrophied.

\section{Sterile $2 b / k(2 b / k)$}

Arbitrary value: 9 .

Meiosis was not observed. The contents of the testis are extremely scarce. In all stages, no more than 10-15 cysts are found per testis, which often coalesce into a single mass. In some males no cysts at all are formed and the testes appear as empty sacs. The number of nuclei per cyst or cystic mass appears to be highly variable, ranging from 10 to more than 90 , instead of the expected number of 64 . All nuclei are found in the tail region. They do not usually elongate, but when they do, they become long threads connected by chromatin bridges.

All spermatids fail to become individualized and the seminal vesicles have no germinal contents.

Testes are always conspicuously atrophied (50-60 per cent in length of D. buzzatii controls, Fig. A2c). 